\title{
ACERCA DE PEDRO SALINAS, POETA
}

Alberto Sauret*

\section{Salinas en su salsa}

“Qué fuerza fría, exterior al hombre, tan secreta que en ella se condensa todo el misterio de la historia, es la que levanta el impulso frenético y ciego de las generaciones?”, 1 se pregunta Dámaso Alonso al referirse al fenómeno de las sucesivas oleadas de poetas que han tenido lugar en España durante la primera parte del siglo y, concretamente, a la que pertenece, más conocida como “Generación del 27”. Denominación que acepta, no sin antes reflexionar: “¿Se trata de una generación? ¿De un grupo? No intento definir. Hace más de un siglo que sesudos germanos están meditando sobre las diferencias, y no han conseguido ponerse de acuerdo."2

En estas páginas me propongo una aproximación a la obra del poeta Pedro Salinas, a tal efecto en primer lugar procuraré ubicarlo en su contexto generacional, acudiendo fundamentalmente a su propio juicio y al de sus coetáneos adscritos al mencionado grupo; para luego abordar en específico un aspecto de su poesía, utilizando un tratamiento semejante, que oportunamente detallaré.

Para el caso me parece muy apropiado traer a colación un trabajo del mismo Salinas donde trata el concepto de generación literaria,

* Departamento Académico de Estudios Generales, ITAM.

${ }^{1}$ Dámaso Alonso, Poetas españoles contemporáneos, 1965, 3a., Madrid, Gredos, p. 177.

${ }^{2}$ Ibid., p. 159. 


\section{ALBERTO SAURET}

aplicándolo a la del 98, para proyectarlo sobre la suya. Allí comienza diciendo que en una serie de artículos periodísticos de Azorín, luego reunidos bajo el título de La Generación del 98 (1913), es donde aparece por primera vez esta denominación que intenta establecer caracteres de comunidad para un grupo de escritores aparecidos hacia principios del siglo. Por la misma época irá afianzándose en la "Ciencia de la Literatura” alemana, inscrita en la tradición que menciona Alonso, una noción análoga: “La denominación que lanzó Azorín, 'Generación del 98', usando el vocablo 'generación’ en sentido genérico, ha pasado ahora, al cobrar ese vocablo un carácter específico, dentro de la historia literaria, a ser una denominación de tipo técnico.”3

Según Petersen, uno de los más conspicuos miembros de dicha escuela, a quien sigue nuestro autor en su desarrollo, para que pueda hablarse con propiedad de generación literaria deben reunirse varios elementos concurrentes, siendo el primero la proximidad entre las fechas de nacimiento de sus integrantes. Los límites que se toman para acotar a la del 27 normalmente son 1891, año que quizá erróneamente $^{4}$ se toma como el de nacimiento del poeta que en especial nos ocupa, y 1905 en el que nace Manuel Altolaguirre, el miembro más joven que se incluye en ella. Media entre ambos un lapso aproximado a los tres lustros, que varios autores coinciden en tomar como apropiado para caracterizar a una generación. ${ }^{5}$

Otro elemento constitutivo de 'generacionalidad' será el de cierta homogeneidad en la formación. Quede señalado por ahora de paso -me

\footnotetext{
${ }^{3}$ Pedro Salinas, Literatura española siglo XX, "El concepto de generación literaria aplicado a la del 98” (1935), 1949, 2a., México, Antigua Librería Robredo, p. 27-8.

4 "En efecto, nació Salinas el 27 de noviembre de 1892, no 1891, como ha señalado Soledad Salinas de Marichal en su edición de las Poesías completas de Salinas, 1975, 2a., Barcelona, p. 32. (Nota del editor.)”, Andrew Debicki, et al., Pedro Salinas, 1976, Madrid, Taurus.

${ }^{5}$ Cfr. Ortega y Gasset, La historia como sistema, Madrid, Revista de Occidente.
} 
detendré luego en ello- que la enorme fuerza formadora que comparten estos poetas es la de la tradición poética española.

También se señala como ingrediente importante el de las relaciones interpersonales. Como lo reconoce D. Alonso en el citado ensayo, y lo acuña José Luis Cano, la del 27 fue la "generación de la amistad”. 6 "Esos escritores no formaban un mero grupo, sino que en ellos se daban las condiciones mínimas de lo que entiendo por generación: coetaneidad, compañerismo, intercambio, reacción similar ante excitantes externos", ${ }^{7}$ dice Alonso, para agregar más adelante que al grupo lo "religaban las afirmaciones estéticas comunes. También las antipatías, en general coparticipadas, aunque éstas fueran, sobre poco más o menos, las mismas que habían tenido la generación anterior (repárese de paso en lo anterior): se odiaba todo lo que en arte representaba rutina, incomprensión y cerrilidad.”8

Un hecho de importancia para ilustrar los estrechos vínculos entre los miembros de una generación será indudablemente el constituido por la participación en las mismas publicaciones, como lo apunta Salinas: "Las revistas son para mí, uno de los indicios más claros para estudiar en lo vivo la preparación de un nuevo estado espiritual.”9 Por su parte J.L. Cano, ejemplificando el apoyo que Juan Ramón Jiménez brindó a los jóvenes poetas, dirá que revistas y cuadernos de poesía editados por éste, como Sí, Índice, Ley, contaron con poemas de casi todos los miembros de la generación. ${ }^{10} \mathrm{Y}$ el mismo autor señala posteriormente la alineación de los poetas en otra etapa junto a la revista Caballo verde para la poesía, dirigida por Neruda, entonces radicado en Madrid. ${ }^{11}$

${ }^{6}$ José Luis Cano, La poesía de la Generación del 27, 1970, Madrid, Guadarrama, p. 11.

${ }^{7}$ Op. cit., p. 168.

${ }^{8}$ Ibid., p. 169.

${ }^{9}$ Op. cit., p. 29.

10 Op. cit., p. 16.

${ }^{11}$ Ibid., p. 21. 


\section{ALBERTO SAURET}

Continúa Salinas en su alocución donde aplica las categorías de Petersen a la Generación del 98, documentando: “A más de las revistas hay otros hechos de mucha significación, en que esa comunidad personal se manifiesta, algunos de carácter anecdótico, como la visita a la tumba de Larra, el banquete a Baroja y, sobre todo, el manifiesto contra el homenaje a Echegaray."12 Para ellos un hecho equivalente será el que tiene lugar en 1927 (por el que toman el nombre generacional de este año) cuando al cumplirse el tercer centenario de la muerte del "prodigioso Góngora barroco” hagan celebrar una misa en su memoria y se enfrenten públicamente a la crítica oficial y académica, al exaltarlo como encomiable ejemplo de búsqueda y realización de la belleza poética.

Así como este acontecimiento ilustra la unión del grupo de poetas en una primera época en la que entre sus inquietudes incluyen la búsqueda de una poesía pura, otro suceso igualmente significativo será el que protagonicen en una segunda etapa, cuando en la citada revista de Neruda se manifiesten por una poesía sin pureza.

Siempre apegándose al dictamen trazado por el mencionado autor, proseguirá Salinas puntualizando el requerimiento de un "acontecimiento o experiencia generacional”. A diferencia de otros momentos históricos, donde hechos de naturaleza política se han señalado como incidentes de relevancia en la labor poética de grupo, en la Generación del 27 los sucesos determinantes no trascenderían el ámbito de lo estrictamente literario. Al respecto dirá Dámaso Alonso: “Lo primero que hay que notar es que esa generación no se alza contra nada ('salvo contra la mala poesía', acotará Cano). No está motivada por una catástrofe nacional, como la que da origen al pensamiento del 98. No tiene tampoco un vínculo político. Ninguno de estos poetas se preocupaba entonces de cuáles fueran las ideas políticas de los otros; varios hasta parecían ignorar que hubiera semejante cosa en el mundo.”13 Palabras muy próximas y afines a las de Jorge Guillén cuando objeta que “eran

12 Op. cit., p. 30.

${ }^{13}$ Op. cit., p. 160. 
PEDRO SALINAS

poetas llamados 'de vanguardia': otra palabreja de aquel tiempo. Aquella metáfora militar no convenía a quienes no luchaban con nadie en ningún frente”. ${ }^{14}$ Antes ha dicho que, “una generación tan 'innovadora’ no necesitó negar a los antepasados remotos o próximos para afirmarse". ${ }^{15}$ (Tómese nota.)

Y continúa Alonso: “La Generación del 98 implica también una revolución literaria contra lo anterior. El modernismo es una nueva técnica, tan destructora de lo viejo como constructiva de una forma y una expresión nuevas. Los poetas de mi generación no abominan de los maestros ya famosos (Unamuno, los Machado, Juan Ramón Jiménez). Más aún: la filiación que respecto a Juan Ramón Jiménez tiene, en parte, el nuevo grupo, es evidente.”16

Piensa Luis Cernuda: "Nuestra tradición poética culterana y conceptista ayudaba al favor dispensado entonces por la metáfora.”17 Como fue señalado, el grupo profesa una enorme admiración por la poética de Góngora, “príncipe de las tinieblas” a quien llegan a admirar hasta el plagio (la frase es de Borges) sobre todo en su arte de plasmar metáforas muchas veces de gran hermetismo, pero también de honda intuición conceptual. Pero, “observemos que ni aún en esto rompíamos con nuestros mayores. El culto a Góngora lo trae a España Rubén Darío, y él lo aprende en el simbolismo francés”; de Verlaine que -acota de paso D. A.- más que conocerlo lo intuye. ${ }^{18}$

Para terminar con este punto señalemos que el acontecimiento generacional determinante en este primer momento será entonces intrínsecamente literario, la ruptura con algunos preceptos del modernismo. Mientras que más adelante la experiencia de la guerra será señalada por la mayoría de los historiadores de la generación como

${ }^{14}$ Jorge Guillén, Lenguaje y poesía. Algunos casos españoles, 1972, 2a., Madrid, Alianza, p. 193.

${ }^{15}$ Ibid., p. 185.

${ }^{16}$ Op. cit., p. 161.

${ }^{17}$ Estudios sobre la poesía española contemporánea, 1972, 3a., Madrid, Guadarrama, p. 37.

${ }^{18}$ Ibid., p. 170. 


\section{ALBERTO SAURET}

acontecimiento decisivo para una nueva etapa del grupo, caracterizada fundamentalmente por el trazado de los caminos singulares de los poetas, que van a vivir experiencias muy variadas respecto del primer momento, cuando constituyen una íntima comunidad madrileña. Si bien tenemos pensado abordar este asunto más tarde, resulta oportuno mencionar la siguiente reflexión: "Las doctrinas estéticas de hacia 1927, que para otros fueron tan estimables, a mí me resultaron heladoras de todo impulso creativo. Para expresarme en libertad necesité la terrible sacudida de la guerra española”, diría Dámaso Alonso. ${ }^{19}$

Menciona también Salinas, siempre sin apartarse del análisis propuesto por el lingüista alemán, el factor del caudillaje. El influjo de Juan Ramón sobre los primeros años de aquella generación fue tan importante como el de Rubén Darío en la modernista. Él constituye el enlace de estos jóvenes con la tradición lírica, sobre todo con Bécquer y, muy importante también, con los cancioneros populares.

En los primeros tiempos la poesía de Antonio Machado no gozaba de prestigio entre los nóveles poetas, le objetaban sobre todo su acentuada encarnación, consecuente sentimentalismo y, por ende, lejanía con una de las inquietudes esenciales que animan la búsqueda del momento, la poesía pura. Hacia ésta, cultivaban una destemporalización de la lírica y la formación de imágenes más en función conceptual que emotiva. Esta práctica sería criticada por el propio Machado, que les achaca un neobarroquismo conceptista -no es casual que admiren a Góngora- frígido y sin alma.

Esta “deshumanización del arte” a la que se refiriera Ortega hacia 1925 predominó en el movimiento en la primer etapa, que correría desde principios de la década hasta aproximadamente 1928. Entonces sienten profundo desdén por lo que califican como "novelesco", que es la poesía con argumento. Guillén por entonces habrá de repetir con entusiasmo conceptos cardinales que le han sido vertidos en forma personal por el poeta del momento que más estima el grupo. Valéry cierta mañana le ha revelado que "poesía pura es todo lo que perma-

${ }^{19}$ Op. cit., p. 157. 
nece en el poema después de haber eliminado todo lo que no es poesía. Pura es igual a químicamente simple." ${ }^{20}$ Como comenta Cano, ese mismo afán de eliminación de los elementos no poéticos que habían invadido la poesía española después de Bécquer es el que van a heredar siguiendo el ejemplo de Juan Ramón, que por entonces predica la poesía desnuda, que persigue la manifestación de la belleza más allá de “su inocencia antigua”, con lo que se está aludiendo su poema con visos preceptivos, en el que, como dirá Salinas muchos años después, "podríamos ver una curiosísima historia de la evolución de su concepto de belleza poética”:21

Vino, primero, pura, Vestida de inocencia;

Y la amé como un niño.

Luego se fue vistiendo

De no sé qué ropajes;

$\mathrm{Y}$ la fui odiando sin saberlo.

Llegó a ser una reina

Fastuosa de tesoros...

¡Qué iracundia de yel y sin sentido!

...Mas se fue desnudando.

Y yo le sonreía.

Se quedó con la túnica

De su inocencia antigua.

Creí de nuevo en ella.

Y se quitó la túnica,

Y apareció desnuda toda...

¡Oh pasión de mi vida, poesía

Desnuda, mía para siempre!

${ }^{20}$ J.L. Cano, Op. cit., p. 19.

${ }^{21}$ Op. cit., "El problema del modernismo en España, o un conflicto entre dos espíritus”, (1938), p. 20. 


\section{ALBERTO SAURET}

Esta actitud estetizante por cierto no será exclusiva del movimiento, sino en cierto modo precedida por los románticos y continuada por todas las vanguardias que habrán de rechazar por un lado el filisteísmo burgués, pero -no se puede negar la cruz de su parroquia-, de extracción burguesa en su mayoría, sobre todo el profundo rechazo por la novedad de su horizonte histórico, "la rebelión de las masas". Aunque, apunta sobre el particular Cernuda: "En general, el poeta moderno, quiero decir el poeta que vive y escribe después de la etapa literaria romántica, ha roto con la sociedad de que es contemporáneo; ruptura donde nada violento hay, sino que se consuma quieta y tácitamente, y ésa es quizá la razón, no la supuesta oscuridad de su poesía, para que la sociedad no guste de ella: porque ya no se reconoce en la obra del poeta." 22 Sin embargo, parecería que tendríamos derecho a sospechar a veces que el poeta contribuye "tantito" a su alejamiento del pueblo. Él mismo nos da elementos en una declaración vertida a la Antología de Gerardo Diego: "Detesto la realidad, como detesto todo lo que ella encierra: mi familia, mi país, mis amigos.”23

Gradualmente la asepsia antirrealista de la generación irá cortando distancias con la vida y tiñéndose con el color de la sangre; herido mortalmente por su tiempo el poeta no oculta ya las máculas que le inflige su vivir, habrá de preferir "el poema con poesía y otras cosas humanas” (Guillén). Hasta que, en una actitud que recuerda a los simbolistas en aquello de que "en arte todo debe ser posible" (o "todo debe estar permitido”) se pronunciarán, como ya dijimos, por una poesía sin pureza mediante un manifiesto en el que reivindican muchos elementos hasta entonces considerados tabú por ellos mismos, que ahora establecen que el acceso a la poesía debe efectuarse sin la renuncia de lo sensorial ni de lo emotivo, "sin excluir deliberadamente nada, sin aceptar deliberadamente nada, la entrada en la profundidad de las cosas en un acto de arrebatado amor, y el producto poesía manchado de palomas digitales..."24

${ }^{22}$ Op. cit., p. 169-70.

23 J. L. Cano, op. cit., p. 19-20.

${ }^{24}$ Ibid., p. 21. 
Este documento, que puede tomarse como el hito que marca el inicio de una nueva etapa para la generación, data de 1935 y fue publicado originalmente por Caballo Verde, la revista comandada por el poeta chileno, recibido con todos los honores por sus miembros que se declaran, “admiradores del joven e insigne escritor americano". ${ }^{25}$ Éste, con otros hechos emparentados habrá de provocar un recíproco alejamiento entre Jiménez y el grupo que, en algunos casos, agravada la circunstancia por el advenimiento de la guerra civil, llegó al rompimiento de relaciones.

La conflictiva situación política de la patria va impregnando y haciéndose carne en los poetas, que de una actitud de manifiesto aislamiento progresivamente asumirán nociones como las de que poesía ante todo debe ser comunicación, y de que sus interlocutores deben ser las mayorías. Esta nueva postura habrá de ser muy importante para considerar oportunamente el deseo de consustanciación con el habla popular de parte del grupo, a efectos de trasuntarla en la nueva práctica poética. En este nuevo punto de madurez poética y humana la figura del maestro Juan Ramón será sustituida por la de Antonio Machado, “con su poesía tan hondamente humana, tan teñida de emoción temporalista, tan preocupada por la realidad y el destino de España”. ${ }^{26}$

Dámaso Alonso en un texto de 1948, donde comenta la fuerte emoción experimentada cierta vez que Juan Ramón desacreditó a su otrora más venerado poeta, al decir: “¿qué es Valéry más que un poeta ripioso?”, se retracta de su posición de 1927 cuando exaltara "el puro placer de las formas”: "Nada aborrezco ahora más que el estéril esteticismo en que se ha debatido desde hace más de medio siglo el arte contemporáneo. Hoy es el corazón del hombre lo que me interesa: expresar con mi dolor o con mi esperanza el anhelo o la angustia del eterno corazón del hombre. Llegar a él según las sazones, por caminos de belleza o a zarpazos."27

${ }^{25}$ Ibid., p. 22.

${ }^{26}$ Ibid., p. 24. 


\section{ALBERTO SAURET}

Con vistas a completar este punto, anotemos que el grupo no contaba con lo que propiamente corresponde llamar un líder, aunque la descollante personalidad de García Lorca lo erigía como presencia más destacada. Comenta Cano que luego de haber compartido horas exquisitas, al repentinamente retirarse Federico, "era como si el dios mismo de la alegría se hubiese alejado, dejando un poso de tristeza en aquella habitación donde, poco antes, había palpitado poderosa la vida”. ${ }^{28}$

Para acabar con los lineamientos trazados por Petersen, dice Salinas que "en los primeros escritos de los hombres del 98 menudean los juicios de disentimiento y de franco ataque con las glorias de la generación pasada”. ${ }^{29}$ Quizá lo más importante que podemos decir en este sentido ya ha quedado señalado, principalmente en el punto anterior; pero, como también se ha dicho, dado que no constituyó esta generación un verdadero rompimiento con la anterior ni tampoco con la tradición lírica española, los ataques siempre fueron moderados. Tomando de Aristóteles aquello de que "las cosas se diferencian en lo mismo que se parecen”, para el caso, a diferencia de aquéllos donde se producen verdaderos rompimientos, resulta más apropiado ver las diferencias como superficiales sobre la continuidad ininterrumpida de un fenómeno.

Dice Pedro Salinas en un ensayo que tituló “El problema del modernismo en España, o un conflicto entre dos espíritus”, que “el modernismo, tal como desembarcó imperialmente en España personificado por Rubén Darío y sus 'Prosas profanas', era una literatura de los sentidos, trémula en atractivos sensuales, deslumbradora de cromatismo. Corría precipitada tras los éxitos de la sonoridad y de la forma. Nunca habían cantado las palabras castellanas con alegría tan colorinesca, nunca antes brillaran con tantos visos y relumbres como en las espléndidas poesías de Rubén Darío”. 30 Pero, como distingue en el otro ensayo que hemos analizado puntualmente, "se ha intentado dar como denomi-

${ }^{27}$ Op. cit., p. 164.

${ }^{28}$ Ibid., p. 14.

${ }^{29}$ Op. cit., "El concepto...”, p. 32.

${ }^{30}$ Op. cit., p. 15. 
nación equivalente a la generación del 98 la del modernismo. Me parece erróneo: el modernismo, a mi entender, no es otra cosa que el lenguaje generacional del 98”. 31 "Si bien no ha habido ningún gran poeta modernista en España, en casi todos los poetas españoles de hoy se siente el provecho de aquella gran conmoción de conceptos y de técnicas poéticos. El modernismo para algunos poetas españoles fue un estado transitorio, para otros un experimento fructuoso. Para ninguno, creo, ha sido un ideal ni una meta. Aprendieron del modernismo para servir necesidades espirituales que iban mucho más allá del modernismo. Y nuestra poesía española tomó otro rumbo (...) camino divergente (...) que no es otro que el de la gran tradición poética viva, no académica, española, la de Garcilaso y Góngora, San Juan de la Cruz y Bécquer."32

Esta auténtica asimilación del influjo modernista para engrandecimiento de la tradición poética hispana será comenzada, desde luego, por los poetas del 91 que cultivaron dicha poética, pero sobre todo será la gran tarea, y con una conciencia de ella cada vez más cabal, de quienes le suceden. Con este sentido debemos interpretar las siguientes palabras de Dámaso Alonso: La herencia, pues, que recibe mi generación es un frío legado, una especie de laboratorio técnico. Pero todo su desarrollo y maduración va a ser -por muchos caminos- un aumento de temperatura humana."33 Para en otro sitio precisar: "La huella gongoriana reforzaba la nitidez de frías perfecciones técnicas, que señalan el destino de los primeros años de aquella generación. Góngora venía a favorecer el culto por la imagen, la ambición universal de nuestros anhelos de arte y el enorme intervalo que queríamos poner entre poesía y realidad."34

En este punto es conveniente destacar algo en lo que habrán de coincidir todos los estudiosos del fenómeno literario, la característica

${ }^{31}$ Op. cit., p. 32.

32 Op. cit., "El problema...”, p. 24.

${ }^{33}$ Op. cit., p. 165.

${ }^{34}$ Ibid., p. 170 . 


\section{ALBERTO SAURET}

de que "aquellos poetas hablaban por imágenes. Y en este punto -la prepotencia metafórica-se reúnen todos los hilos”, como ha precisado Guillén. ${ }^{35}$ Pero, como hemos venido destacando, la reacción poética de estos jóvenes, justamente por ser honda afecta el espíritu poético sin acusar ninguna estruendosa ruptura superficial más o menos inconsecuente, como fuera el destino de otras 'insubordinaciones'. El cultivo de la metáfora es característica común de todos los movimientos de la época que se levantan contra el amaneramiento vacuo por el que tiende a derivar la poesía de principios de siglo, no obstante, como lo hace notar Cernuda, “el cultivo de la metáfora no era ninguna novedad; sin ir más lejos (...) Campoamor, a quien los poetas innovadores de $1925^{36}$ tenían por 'putrefacto', consideraba la metáfora como esencial a la poesía. Propio de ellos será entonces un interés por la elaboración metafórica que supere lo meramente sorprendente, ingenioso y críptico para calar a mayores honduras metafísicas, intención quizá no completamente manifiesta en una primera etapa, pero indudable en los años posteriores. En este punto, de los autores consultados, es en Cernuda en quien observo un mayor criticismo, un verdadero disentimiento escéptico en algunos casos, posiblemente, como modestamente sospecho, por no pertenecer propiamente al grupo y, al mismo tiempo, conocerlo desde dentro.

Quizá Cernuda, ya en las fronteras, muestra las primeras desavenencias de un “conflicto generacional”. Así, mientras que Guillén dirá que, "el efectismo es lo que se prohíben estos poetas”, 37 él opinará que "en sus comienzos, los poetas de la generación de 1925 (...) introducían en sus versos demasiadas metáforas voluntarias y efectistas, (para luego admitir que después de 1930) la metáfora caprichosa y relumbrante no aparece ya”. ${ }^{38}$ Guillén agregará -como descargo-: "Nunca falta lector o espectador que sospeche malicia, truco, insinceridad,

${ }^{35}$ Op. cit., p. 188.

${ }^{36}$ Op. cit., p. 156.

${ }^{37}$ Op. cit., p. 192.

${ }^{38}$ Op. cit., p. 157. 
ansia de fama en pintores o escritores de veras nuevos -sin advertir que están jugándose la vida a cada pincelada, a cada rasgo.”39 Esta polémica será particularmente interesante recordarla cuando veamos con exclusividad a Salinas, que fuera maestro de Cernuda y a quien éste va a criticar muy duramente, achacándole haber extraviado su camino por influjo de su íntimo amigo, Guillén, y caído en una poesía apantallante y sin auténtico valor intuitivo.

Para ir dando término a esta primera parte introduciremos otros conceptos de los autores a los que hemos recurrido, que más que agregar algo sustancialmente diverso a lo visto, nos habrán de servir de corolario.

"Si la primera nota característica del grupo fue la predilección por la metáfora, la segunda fue la clasicista”, establece Cernuda, que para ilustrar la afirmación acude a un verso de un poeta tan poco "clasicista" como Lorca: "Un deseo de formas y de límites nos gana.” 40 Él mismo agregará más adelante: "La influencia de Góngora combinada con la actitud clasicista, tuvo otra consecuencia, que es la reaparición de la métrica (...) y de las estrofas (...) en su forma ortodoxa."41

Ahora es Guillén: "La ruptura con el pasado fue mucho mayor en las generaciones contemporáneas de otros países. A la herencia española no se renunció, y esta herencia no coartó el espíritu original. ¿Qué poeta de entonces francés, italiano (...) se habría atrevido a escribir sin ruborizarse un soneto?"42

Es la parábola completa de una ola que luego de alcanzar su máximo valor de cresta individualizada y rampante se derramará plena y gozosa sobre las playas siempre nuevas, siempre inquietas de la poesía, para descender a fundirse con su sustancia primordial e integrarse con los renovados fervores. "Nacía con frialdad heredada y terminó volcán; nacía como vuelta a la forma y terminó en frenesí de libertad.”43 Li-

${ }^{39}$ Op. cit., p. 193.

${ }^{40}$ Op. cit., p. 157.

${ }^{41}$ Ibid., p. 160.

42 Op. cit., p. 194.

${ }^{43}$ Alonso, op. cit., p. 177. 


\section{ALBERTO SAURET}

bertad de veras, no mera rebeldía pecado de juventud, que afianza sus logros sobre los de quienes le precedieron, de quienes, con suprema libertad creadora, no tienen necesidad, intenciones ni deseos de renegar, sino de abrazar en el compartido amor por la poesía, que es “el signo de la literatura española del siglo $\mathrm{XX},{ }^{44}$ que ha de vincular íntimamente el nuestro con los momentos de mayores glorias de la poesía en lengua castellana.

"En este período de 1920 a 1936 confluyen dos poderosas generaciones poéticas en actividad: una la de los maestros: Unamuno, los Machado, Juan Ramón; otra ésta de que venimos hablando. Hay que ir al Siglo de Oro y pasar por alto allí mucha rutina, mucho culto a la forma externa (...) para encontrar algo semejante a la confluencia de generaciones poéticas en las que hemos vivido”, 45 que Guillén, con menos circunloquios no vacilará en calificar como "Nuevo Siglo de Oro”.

\section{La mirada del poeta}

Opina Cernuda que, ni por la edad ni por el espíritu, tanto Salinas como Guillén pertenecen propiamente a la misma generación, sino que más bien serían poetas de transición entre la que llama del 25 y su precedente. Cuando ellos publican sus primeras obras cuentan respectivamente 35 y 32 años. "Salinas, el de más edad, después de algunos poemas publicados en revistas (no falta algún ejemplo muy inmaturo y muy distinto de lo que va a ser su arte), aparece ya cuajado en un libro intenso: Presagios (1923)."46

La lírica de Salinas quedará como una de las más ricas de subjetividad e intimidad de la poesía española amorosa”, comenta José Luis Cano, ${ }^{47}$ más moderado en la valoración que Julián Marías quien con-

${ }^{44}$ Pedro Salinas, op. cit., "El signo de la literatura española del siglo XX" (1940), passim.

${ }^{45}$ D. Alonso, op. cit., p. 176.

${ }^{46}$ Op. cit., p. 166.

${ }^{47}$ Op. cit., p. 53. 
sidera que representa lo que en otros tiempos fueron Garcilaso y Bécquer; ${ }^{48}$ y que Guillén para el que La voz a ti debida y Razón de amor sólo son comparables en calidad poética con las Rimas del gran romántico español y con el Canto a Teresa de Espronceda. ${ }^{49}$ Mientras que D. Alonso haciendo un reconocimiento crítico de su poesía habrá de referirse de la siguiente manera: "Salinas cultiva un verso flojo, con voluntarias irregularidades métricas, sin rima o en asonante; la forma en él es más bien interior, una felicidad en el hallazgo del tema,

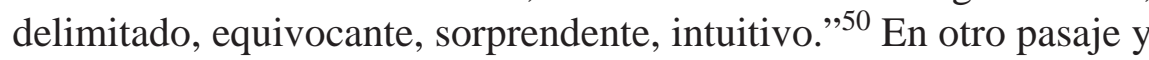
refiriéndose en especial a su primer época dirá: “Salinas tenía la fertilidad ingeniosa, la deliberada incongruencia (...) elementos que, como rozan el humor, el lector capta pronto; y, además, un sentido deportivo, una fe tan de aquellos años, que el lector se sentía, cerrando los ojos, bien en aquel mundo y concorde con él.”51

Luego, en el período que tiene lugar entre 1927 y 1936, como dice también Alonso, ocurren cosas muy graves, "ha comenzado una nueva época de poesía española: época de grito, de vaticinio, o de alucinación, o de lúgubre ironía". ${ }^{52}$ En lo que hace a la vida nuclear de la generación, “los vínculos se van lentamente relajando, y, por lo que toca al concepto mismo de lo poético, se abre aquí, diríamos, una importante herejía. Pero es en este segundo período, precisamente cuando los poetas llegados antes al arte literario (Gerardo, Salinas, Jorge, Alberti y Federico) han alcanzado la plenitud de sus facultades”. ${ }^{3}$ Por su parte Guillén considera que Pedro Salinas se creció mucho en América y nunca fue tan fecundo como en el decenio del 40". 54

El mismo Guillén, su entrañable amigo, habrá de decir que no existe propiamente un lenguaje poético, mas sí "lenguaje de poema”: "La

${ }^{48}$ Ibid., p. 52.

${ }^{49}$ Ibid., p. 53.

${ }^{50}$ Op. cit., p. 167.

${ }^{51}$ Ibid., p. 173.

${ }^{52}$ Idem.

${ }^{53}$ Ibid., p. 171.

${ }^{54}$ Op. cit., p. 196. 


\section{ALBERTO SAURET}

poesía no requiere ningún especial lenguaje poético. Ninguna palabra está de antemano excluida; cualquier giro puede configurar la frase (...) sólo es poético el uso, o sea, la acción efectiva de la palabra dentro del poema”. ${ }^{55}$ Traemos a caso esta reflexión, que en un primer momento puede resultar intempestiva, porque se trata de una transición que nos ha de servir de enlace al siguiente aspecto a tratar.

Ahora tomaremos algunas consideraciones vertidas por el poeta en su valioso libro de ensayos El defensor (1948), producto de su etapa americana, con el fin de revertirlos sobre algunos pasajes de su obra poética, acudiremos también al mencionado ensayo “El signo...”, asimismo a algunos conceptos suyos extraídos de otros trabajos, como a algunos comentarios oportunos de sus conocedores. Creemos que este procedimiento puede conducirnos a extraer ciertos caracteres esenciales del espíritu del poeta (a hacernos saber el gusto de la mera sal de Salinas).

Antes de observar algo de lo que él piensa sobre el uso lingüístico, atendamos la advertencia hecha por Cernuda: "Es común a todos ellos, al menos durante los quince o diez años primeros de su labor, lo hermético del pensamiento poético y un estilo que tiene como norma el lenguaje escrito; luego con mayor o menor lentitud, la mayoría de ellos evoluciona hacia un estilo cada vez más cercano a la pauta del lenguaje hablado, siendo la expresión más directa y la dicción más clara.”56 Evidentemente esta observación corresponde con los últimos conceptos tomados de Guillén, también sin duda con lo que creía Salinas: “Según Vendryes ha dicho: 'en la actividad lingüística de un hombre civilizado normal están en juego todas las formas de lenguaje a la vez’. Y yo, por mi parte, no sé a veces distinguir si una frase feliz que está en mi memoria la aprendí de unos labios, en palabra dicha, o de un libro, de la palabra impresa. Sería insensatez oponer las dos formas del habla; y toda educación como es debido debe ponerse como finalidad una integración profunda del lenguaje hablado y el escrito."57 “El poeta acrece las posibilidades del lenguaje vivo en grado sumo. Y su obli-

${ }^{55}$ Ibid., p. 195.

${ }^{56}$ Op. cit., p. 168.

${ }^{57}$ Pedro Salinas, El defensor, 1983, Madrid, Alianza, p. 289. 
gación no es solamente repetir, sino renovar el espíritu del lenguaje. 'Antes de que el poeta viniera con su obra nadie sabía de lo que era capaz una lengua, lo que era cabalmente’.”58 Quizá no esté de más recordar aquí lo dicho antes sobre la suma importancia que otorga la generación a la metáfora, esa búsqueda apasionada por retorcerles el pescuezo a las palabras cotidianas para extraerles el hálito que han perdido, que los menesteres materiales no le exigen.

Abundan los testimonios de la enorme dicha que experimentó Pedro Salinas cuando, luego de su permanencia en Estados Unidos tuvo oportunidad de visitar distintos lugares de hispanoamérica y, sobre todo, la alternativa de radicar durante un prolongado período en Puerto Rico; “en San Juan pasó los tres años más felices de su destierro”, afirmará su hija. ${ }^{59}$ Ella también dirá: "Si por los ojos le entraba el mar, un mar nuevo y viejo a la vez, porque con él volvía el recuerdo de los veranos felices pasados a orillas del Mediterráneo en Alicante, por los oídos le llegaba el español vivo de la calle y el descubrimiento de giros y palabras americanos."60 Relata además su hija que cierta vez de paso por "México se hizo imprimir una tarjeta que resume muy bien su reacción ante Hispanoamérica: ‘Pedro Salinas, el extranjero en su patria’.”61 Pequeño hecho cargado de significación a la luz de la frase de Vossler, de la que don Pedro se apropia en un muy sustancioso ensayo: "Cuando a los hombres se les despoja de su tierra, encuentran como un nuevo hogar en su lengua madre, que está a todas horas y en todas partes presente en sus sentidos, y por eso puede volver a convertirse en algo concreto, en con morada terrenal. 'Cuando el sentimiento nacional ha sido despojado de todos los refugios, el lenguaje se convierte en la fortaleza espiritual desde la que un día, cuando los tiempos sean propicios, saldrá a reconquistar su puesto’.”62

${ }^{58}$ Ibid., p. 220.

${ }^{59}$ Solita Salinas de Marichal, "Recuerdo de mi padre”, en Debicki et al., op. cit., p. 40.

${ }^{60}$ Idem.

${ }^{61}$ Ibid., p. 39.

${ }^{62}$ Ibid., p. 288. 


\section{ALBERTO SAURET}

Por cierto en el mar, al que le canta en el primero de sus libros americanos, El contemplado, creemos ver varios símbolos; pero ya que estamos donde estamos, digamos que su vastedad, su infinitud es también la del lenguaje, que hace posible que todo mundo sea mundo cuando el poeta lo nombra, lo funda, lo crea.

Como adelantamos, Cernuda piensa que lo más valioso y auténtico hecho por Salinas pertenece a Presagios, que a excepción de su primer libro prevalecerá en él “una especie de temor a tocar temas o situaciones donde apareciese lo humano fundamental”. ${ }^{63}$ Piensa que para aquél la creación poética antes que la captación de una realidad más honda que la aparente ha consistido en un juego de ingenio y llega a decir que tanto en La voz a ti debida como en Razón de amor, el amor, que es el tema de ambos le parece “otro juego; y si no juego, afectación: deseo de mostrarse tan humano como el que más”. ${ }^{4}$

Nosotros, con todo el respeto que nos merece el juicio del discípulo del poeta que nos interesa, sin un mayor conocimiento de la poesía de Salinas, mejor dicho, sin mayor conocimiento de la poesía sin más, es decir con todo la modestia que demanda semejante indigencia, disentimos de Cernuda. Creemos ver en su primera obra propiamente un presagio, indicios de lo que irán siendo a lo largo de su vida y obra hallazgos, revelaciones mayores y conexas, nos parece que el poeta va calando en honduras mayores de la realidad con absoluta certeza, sosiego y dicha.

Dado el exiguo tiempo de que disponemos, ${ }^{*}$ habría sido en varios sentidos imprudente proponernos este trabajo a partir de un análisis que abarcase la totalidad de su obra poética. Hemos creído conveniente tomar entonces la que consideramos su mejor antología, que es la realizada y editada por Jorge Guillén, donde encontramos poemas selectos de todos los momentos y obras de Salinas.

${ }^{63}$ Op. cit., p. 173.

${ }^{64}$ Ibid., p. 174.

* Este trabajo fue elaborado para el módulo La Generación del 27, dictado por Arturo Souto en el Diplomado de literatura contemporánea del ITAM en 1989. 
PEDRO SALINAS

A modo de enlace con el propósito que adelantáramos y al mismo tiempo para mostrar un disentimiento con la apreciación de Cernuda, basándonos en la certera observación de uno de sus más destacados críticos, veamos el particular tratamiento que da el poeta en su particularísima lírica al tema lírico por excelencia, el amor. Como hace notar Cano, en La voz a ti debida, el poeta no canta al amor de manera abstracta, ni a una amada que es pura idealización, sino a la mujer temporal, de carne y hueso. Esta amada corpórea, concreta es por cierto idealizada por el amante, pero no en las notas de su belleza o en su profundo misterio, como lo es en la poesía de los románticos, sino en su capacidad de artífice de un mundo más que maravilloso maravillado porque es el que ve el poeta enamorado. Es el mundo de los sentidos que adquiere sentido más pleno por el amor, que sin dejar de ser ideal es el que materialmente vive con su amada. Los siguientes versos son muy ilustrativos al respecto. Alude en los primeros una suerte de universo platónico, donde las cosas son en una pura virtualidad, como apenas sospechada por el poeta:

Las ciudades, los puertos

flotaban sobre el mundo

sin sitio todavía:

para que por la palabra primorosa de la amada adquirieran corporeidad, fueran de modo concreto y singular, para que cobraran consistencia en la propia vida del poeta enamorado

esperaban que el tú

les dijeses: “Aquí”65

65 Jorge Guillén, selección y prólogo, Poemas escogidos de Pedro Salinas, Buenos Aires, Espasa Calpe, 2a., nov. 1953, p. 60-1. Los números entre paréntesis que aparecen junto a los poemas corresponden a las páginas de esta edición. 


\section{ALBERTO SAURET}

La amada no es propiamente aquí un ser prodigioso, como podría haberla querido un romántico, sino una simple mortal investida de los naturales poderes que prodiga el amor humano o, quizá mejor dicho, la naturaleza a través de la comunicación humana, amorosa.

En sus trabajos de América (El Contemplado, Todo es más claro y Confianza) el amor, si bien no habrá de desaparecer por completo, cederá ante la inquietud de otros temas y preocupaciones que, queremos mostrar, están presentes ya en la primera parte de su obra, es decir, experimentan un desarrollo en ella, con ella. En este punto adherimos con Brehm, quien dice, "lo importante es ubicar la poesía de Salinas dentro de una trayectoria literaria para percibir mejor sus características". 66

Accederemos por la brecha que abre Ricardo Gullón: “Los libros de poesía de Pedro Salinas llevan títulos que conviene recordar: Presagios, Seguro azar, Fábula y signo, La voz a ti debida, Razón de amor, El Contemplado y Todo más claro. Un buen título -y éstos lo sondebe ser significativo y sintetizar la idea del autor sobre su libro, sobre el contenido de su libro. (...) Aluden todos a una interpretación de los fenómenos y no a los fenómenos mismos. Están puestos subjetiva y no objetivamente, en atención a los reflejos suscitados por la realidad del poeta." 67

Qué bien lo conoce Guillén -meridiano para todos los interesados en su amigo. Para el prólogo a Poemas escogidos piensa, "la poesía de Salinas es (...) un mundo profundamente acompañado por un alma”, versión personalizada de una reflexión anterior: "Se desea lo real, pero convertido en espíritu dentro de quien lo humaniza y poetiza":68 Es también ésta la misma íntima convicción de Salinas, que en distintas partes de su El defensor insiste con lo establecido por Vossler: "El

${ }^{66}$ Luis Fernando Brehm, Los signos del aguamarina en Pedro Salinas, 1979, México, Cuadernos politécnicos de ciencia y cultura, p. 24.

${ }^{67}$ Ricardo Gullón, “La poesía de Pedro Salinas”, en Debicki et al., op. cit., p. 85.

${ }^{68}$ Guillén, Poemas..., pról., p. 11. 
genio poético se reconoce por su don de reconvertir la naturaleza del lenguaje en espíritu, sus formas exteriores en algo interior, devolviéndole el alma que se destruyó en el habla ordinaria." ${ }^{69}$ Encontramos una confirmación de ello en Ángel del Río cuando sostiene que en esto consiste sustancialmente "la teoría poética de Salinas para quien todo lirismo, toda poesía resulta siempre de un eterno conflicto entre la realidad externa y el espíritu creativo del poeta que aspira a crear una realidad más alta y permanente". ${ }^{70}$

Vamos a algunos de sus pasajes poéticos que resultan más reveladores a nuestros propósitos (los subrayados siempre serán míos).

Triunfo suyo

No se le ve, pero está detrás, seguro imperial rostro insufrible, dueño de lo último.

.....

Lo eterno, suyo. Vendrá, -iqué bien le siento!- por ello.

Voy a verle cara a cara:

porque ya se está quitando, porque está tirando ya, los cielos, las alegrías, los disimulos, los tiempos, las palabras antifaces leves que yo le ponía contra -iirresistible luz!rostro de sin remedio eternidad, él, silencio. (38)

${ }^{69}$ Idem.

70 Ángel del Río, “El poeta Pedro Salinas”, en Debicki et al., op. cit., p. 22. 


\section{ALBERTO SAURET}

Brehm -que dicho sea de paso disiente con quienes ven en Salinas una visión mística $-{ }^{71}$ comentando el anterior dice: "No dice la palabra Dios en todo el poema pero todas refieren a su presencia. Es concebido con algunos de sus atributos: invisibilidad, sustentación, sin padecimiento, ser eterno, de acuerdo con la fe del cristianismo."72 No estoy de acuerdo, este poema me sugiere más bien una visión de tipo pagana. Concretamente, al decir “dueño de lo último” me recuerda a Cicerón -traductor de Aristóteles-cuando en su lecho de muerte se encomiende a la "Causa de las causas", que es otro modo de aludir al Motor inmóvil de su maestro. Pero las nociones predominantes en toda la obra de Salinas antes que aristotélicas son -ya adelantamos algo- platónicas y anteriores también, familiares a los presocráticos.

En este poema, particulares resonancias platónicas tienen dos pasajes:

No se le ve, / pero está detrás

.....

Las palabras, antifaces / leves que yo le ponía

114 Es una constante en Salinas esta noción platónico-parmenídea de lo esencial oculto y lo engañoso de las apariencias, así como la idea de que la palabra poética no es veraz. Y hasta la resignación es platónica, pues Platón cuando no puede aclarar algo por medio del concepto acude al mito. Pero Salinas sabe que lo único que tiene es la palabra poética, que no le permitirá alcanzar la contemplación plena de lo absoluto, pero le irá haciendo posible ver todo más claro, ésta es su fe y busca la salvación por ella. Comenta Brehm: "En la obra de Salinas existe siempre el deseo de captar el lenguaje de los objetos, pero una imposibilidad de lograrlo. Salinas no duda de la existencia de la realidad, pero se le presenta cubierta de velos. Por esa razón busca siempre detrás de lo que es. Al no encontrar la satisfacción deseada, el canto de los poemas se convierte en una búsqueda...

${ }^{71}$ Brehm, op. cit., p. 11.

${ }^{72}$ Ibid., p. 23. 
el canto del deseo de aclararse lo que presume que está latiendo en el campo de la realidad."73

Hay una línea ininterrumpida de consumación de su pensamiento desde Presagios (1923) hasta Confianza (póstumo), donde lo que en un primer momento se presenta como indicio, sospecha, prefiguración paulatinamente irá cobrando confirmación, certeza: "Por el poema el poeta se aclara en algún grado lo que busca."74 Aclara, agregamos, hasta donde es posible aclarar la vista humana. Salinas a lo largo de su obra radicaliza su intuición primera, exhibe la convicción de que lo vislumbrado es cierto y lo es cada vez más.

Líneas más arriba he rechazado la interpretación de Brehm, que quiere ver en un poema de nuestro autor la manifestación de una espiritualidad cristiana. No sé si Salinas profesaba esta confesión. A veces nombra a Dios, así con mayúscula, por lo que podríamos suponer en él una idea monoteísta, pero no es el caso del poema en cuestión, ni tampoco el de su obra en general. Por supuesto que hay latente siempre en Salinas la expresión de la experiencia de lo sagrado, que en muchos momentos, contrariamente a lo que sostiene Brehm, permite ver una proximidad con la de algunos místicos, pero el sentimiento que inspira a Salinas parece ser el de una comunión con lo absoluto mundano, terrenal, más que con una noción de lo absoluto como trascendente sobrenatural. El deísmo de Salinas se muestra 'naturalista', de tipo panteísta, y aquí sobre todo es donde hallamos al poeta muy próximo a los presocráticos -tanto como lo estuvo Nietzsche. (Quizá, no lo afirmo, no lo sé, hasta en esto un hombre de la Generación del 27 no haya roto con su pasado inmediato. Como se ha dicho, Nietzsche fue de los pensadores que tuvo una gravitación particular sobre la Generación del 98, en especial sobre Unamuno.)

Pero, según lo previsto, veamos momentos de la obra en disposición cronológica, en primer lugar, fragmentos de Presagios, su primer volumen publicado.

${ }^{73}$ Ibid., p. 28-9.

${ }^{74}$ Ibid., p. 5. 


\section{ALBERTO SAURET}

Forjé un eslabón un día, otro día forjé otro

y otro.

De pronto se me juntaron

-era la cadena- todos. (17)

Aunque la alusión pueda resultar aún vaga aquí, la figura de la cadena está sugiriendo lo que luego va a ser expuesto de modo patente, la idea de eslabones que se van engarzando hasta concluir un ciclo, una circularidad, una recurrencia, la idea del eterno retorno, común en las sociedades arcaicas, en la antigüedad grecolatina y que será retomada por Nietzsche. Como coinciden en señalar los mitólogos, la figura del eterno retorno está estrechamente ligada a la observación de los cielos astronómicos y a la paralela regeneración de la naturaleza. Esta visión de apego a lo estrictamente natural, terreno, inmanente la vemos claramente en el poema inmediato:

Suelo. Nada más.

Suelo. Nada menos.

Y que te baste con eso.

Porque en el suelo los pies hincados, en los pies torso derecho, en el torso la testa firme, y allá, al socaire de la frente, la idea pura, y en la idea pura

el mañana, la llave -mañana- de lo eterno. Suelo. Ni mis ni menos.

Y que te baste con eso. (17)

Nótese aquí que lo señalado con anterioridad resulta remarcado con el hecho de que la idea no finca en un 'más allá', sino que tiende a lo más alto, pero se sabe tributaria del cuerpo enraizado en la tierra. El poema concluye enfatizando el necesario y total apego a lo exclusiva- 
mente terrenal, pero antes ha dicho lo que corresponde a la idea pura (de nuevo Platón), que para el poeta es la palabra poética (etimológicamente, creadora) capaz de entrever lo verdadero, lo que de veras es, atisbar la eternidad y de este modo salvarse por el conocer. La palabra del poeta funda el orden del conocimiento verdadero y en éste se fundamenta la fe.

Del segundo volumen de poemas, Seguro azar (1929), ya hicimos algunos comentarios sobre "Triunfo suyo"; luego de lo agregado destaquemos ahora la nueva presencia del tema de lo eterno, que con certeza sabe el poeta, vendrá. Y, lo repetimos, aquí vemos estriba su credo. Nos parece muy clara su presencia en el poema del mismo libro titulado, precisamente "Fe mía”:

-....

De ti, que nunca te hice, de ti, que nunca, te hicieron, de ti me fío, redondo seguro azar. (36)

Éste nos parece testimoniar cabalmente nuestras hipótesis. "De ti que nunca te hicieron” es una expresión precisamente contraria a la de un Dios creador. Mientras que al azar se le atribuye carácter de inescrutable, ineluctable e infalible. Los detalles son los que debe intuir y aludir con la palabra sugestiva, reveladora el poeta, pero sobre lo que no caben dudas es que es redondo, como no duda Nietzsche cuando más o menos dice, "lo que me trajo me ha de volver a traer".

También a esta obra pertenece "Vocación”, donde Salinas habla de sí, pero también de lo que es propio del poeta impersonalizado, de cualquier hombre que reconozca en sí la vocación (el llamado de su voz interior) de poeta y responda a ella con fidelidad. Los primeros versos hablan de la mirada vulgar, conforme, satisfecha con el orden establecido (doxa), que resbala por los lugares comunes y no es capaz de descubrir nada sorprendente, inquietante. La segunda parte, de lo que dijimos antes, del trabajo del poeta que otea y nombra y con ello continúa en la proporción humana la tarea del octavo día. 


\title{
ALBERTO SAURET
}

\author{
Abrir los ojos. Y ver \\ sin falta ni sobra, a colmo \\ en la luz clara del día \\ perfecto el mundo completo \\ que le dé la perfección. (29)
}

Viene muy a caso ahora la observación hecha por Brehm: "La inquietud por la palabra que vive en las poesías de Salinas está en relación con la petición de la palabra del poema '17' de Eternidades de Juan Ramón Jiménez:

¡Inteligencia, dame

el nombre exacto de las cosas!

...que mi palabra sea la cosa misma, creada por mi alma nuevamente.,75

${ }^{75}$ Ibid., p. 30. 
Y aquí la tentación es irresistible, voy a incluir una cita del propio Salinas que venía reservando para colofón, como "tesis de la tesis”, según sugiriera usted Maestro.

"El poeta adelantado. Esto es natural. Porque el poeta, el creador latu sensu, es equiparado, según tradicional paralelo, con el vidente, ve más largo que los demás, que los prójimos que viven a su lado, en sus años. La distintiva del poeta es estar dotado de una penetración de visión, de una vista espiritual superior. Se la ofrece a sus semejantes, al publicar la obra. Por él pueden ellos ver lo nunca visto. Es como maravilloso vidrio de telescopio que descubre estrellas en cielo donde no se veían."76

Como señalan varios estudiosos de su obra, el mar que será una figura tan importante en la última parte no está presente en sus primeros trabajos. Ángel del Río dice que por la circunstancia de haberse casado con una alicantina, con familia en Argel, Salinas pasó muchas temporadas junto al Mediterráneo, "una visión, una mirada, una intuición que va madurando". ${ }^{7}$

Hallamos al mar por primera vez en un poema de Fábula y signo (1931), que muy significativamente titula "Mar distante", donde vemos algunos elementos en germen llamados a florecer en El Contemplado. Guillén dice que con el mar Salinas se refirió al universo todo, numerosos críticos agregarán comentarios semejantes, que no por obvios dejan de ser imprescindibles para tratar su obra, tales como que el mar es un símbolo de lo absoluto, de la infinitud y cosas por el estilo. El mencionado poema parece claramente confirmar este tipo de interpretaciones; veamos:

Si no es el mar, si es su imagen, su estampa, vuelta, en el cielo. - . . .

${ }^{76}$ P. Salinas, El defensor, op. cit., p. 246.

${ }^{77}$ Op. cit., p. 21. 


\section{ALBERTO SAURET}

Si no es el mar, si es su idea

de fuego, insondable, limpia;

y yo,

ardiendo, ahogándome en ella. (41/42)

Aquí nos presenta al mar como réplica especular del cielo, inconmensurable (topos uranós), pero termina diciendo que más que el mar es la idea del mar lo esencial, lo que produce vértigo y consume al poeta, donde debe nadar con palabras para salvarse de la desesperanza.

El próximo volumen fue construido como poema único y es de los más conocidos del poeta. La voz a ti debida (1933), al cual ya nos hemos referido, seguramente es lo más importante que produjo el poeta en cuanto a poesía amorosa. Oportunamente, y siguiendo a Cano, señalábamos la ‘proporción humana' de la amada que nombra Salinas, a diferencia de lo que fue la figura femenina para el poeta romántico; esto obedece elementalmente al fuerte sentimiento terreno presente siempre en su expresión poética. Pero sin renunciar a su inmediatez, a lo más humano, corpóreo, singular y contingente, el poeta mira, busca y ve en lo particular y actual guiños de una realidad más honda. Como apunta Guillén, aquí “el Más Allá no exige la anulación del Más Acá”, 78 El poeta ama a su amada en tanto que es la que es, pero siente que su sentimiento arraiga en algo más profundo y desciende, primero a la búsqueda de la mujer primordial y luego hasta fundirse con ella en la vida toda que se quiere a sí, indiferenciada, indivisa, plena, primordial.

Dice: “Detrás, más allá te busco.” Pero a esta búsqueda que llega hasta la confusión con la materia misma del mundo, el poeta la concibe como despojo, la emprende desandando, como regresión al seno de la madre tierra, hasta el polvo primigenio, donde vemos reaparecer muy claramente el tópico del retorno.

El otro punto que destacamos como fundamental en su poética, el de la mirada, es con el que inicia este extenso poema. La búsqueda que traza su desarrollo se inicia con una doble negación, que enfatiza

${ }^{78}$ Prólogo, p. 13. 
el requisito primero: “No, no dejéis cerradas/las puertas de la noche”, es decir, dame luz, déjame que pueda mirar, permíteme ver(te, y en ti y contigo verme), buscarte deshaciendo, destejiendo la trama superficial tejida por la historia.

Toda hacia atrás la vida

se va quitando siglos,

frenética, de encima;

desteje, galopando,

Para luego dibujar nuevas alegorías a la figura momentánea, a la paradoja de la temporalidad, al curso y recurso de un tiempo que se repite, que recuerda el futuro, que proyecta el pasado.

anhelo de empezarse

otra vez. El futuro se llama Ayer

.....

¡Atrás y siempre atrás!

¡Retrocesos, en vértigo,

por dentro, hacia el mañana!

Y ya siento entre tactos, entre abrazos, tu piel

que se me entrega al retorno

al palpitar primero,

sin luz, antes del mundo,

total, sin forma, caos. (64)

.....

en una jubilosa

repetición sin fin

de tu amor, unidad. (65)

.....

Rendirse

a la gran certidumbre, oscuramente (66) 


\section{ALBERTO SAURET}

Nuevamente, es el atisbo infalible, indubitable de algo que es a medias escrutable, pero ineluctable, la seguridad de una verdad que nunca puede ser confundida con la superficial precisión, que se conforma a la medición de lo aparente; que ha calado en lo más hondo y visto que en el fondo hasta las contradicciones de los opuestos son meras apariencias insignificantes.

Vemos también en este poema un adelanto de lo que constituye la 'alta' confianza del poeta, que es la de trascendencia de todo lo particularizado, incluso del amor de pareja, que sin negar a éste busca una comunión plena, absoluta.

Y todo enajenado podrá el cuerpo

descansar, quieto, muerto ya. Morirse

en la alta confianza

de que este vivir mío no era sólo

mi vivir: era el nuestro. $Y$ que me vive

otro ser por detrás de la no muerte. (66)

....

En la noche y la trasnoche y el amor y el trasamor, ya cambiados en horizontes finales (69)

Esta búsqueda confiada evoca la idea de enajenación agustiniana, hoy contaminada por diversas vicisitudes, con la que el de Hipona anhelaba fundirse en un abrazo con Dios. Pero Agustín era también platónico; y Salinas lo es una vez más cuando continúa:

¿Las oyes cómo piden realidades

ellas, desmelenadas, fieras, ellas, las sombras que los dos forjamos en este inmenso lecho de distancias?*

* El abrazo carnal es aún separación plural, imposibilidad de comunión absoluta, fusión; distancia de la materia, que proyecta sombras que se enciman sin lograrse penetrar, coincidencia de soledades. 
PEDRO SALINAS

Cansadas ya de infinitud, de tiempo

sin medida, de anónimo, heridas

por una gran nostalgia de materia,

piden límites, días, nombres. (69)

La visión mortal, encarnada, encadenada al opaco cuerpo es mera sombra que añora nostálgica despojarse de su contingencia material para, atravesando este universo de ilusorias réplicas, volver a ver lo que de veras es, a contemplar, que es ver sin velos. La simple mirada mortal no puede trascenderlos, la del poeta, que es medio divina, desvela. La mirada poética rompe las humanas ataduras, se eleva hasta ver el origen de las sombras y con ello se aproxima a la contemplación, luego da cuenta a los demás ensombrecidos mortales de lo visto, recreando su visión: poiésis.

La próxima será su otra gran obra de poesía amorosa, que a diferencia de la anterior será un conjunto de poemas; según los estudiosos, de gran calidad pero inferiores a aquél. Para nuestro propósito tomamos una de las poesías de Razón de amor (1936), donde encontramos, de entrada, una metáfora de los ojos, desde Aristóteles 'ventanas del alma'.

Ya está la ventana abierta.

Tenía que ser así

el día. (85)

Mundo de lo prometido, agua.

Todo es posible en el agua.

Apoyado en la baranda, el mundo que está detrás en el agua se me aclara, y lo busco

en el agua, con los ojos, con el alma, por el agua. (96) 


\section{ALBERTO SAURET}

El poema resulta diáfano, junto con la mirada del poeta que se va aclarando, el simbolismo del agua, del mar va cobrando mayor importancia Agreguemos simplemente que él se ve junto a la baranda, frontera y atalaya de la inmensidad y que estos versos anteceden en diez años a los de El Contemplado (1946).

Esta otra gran obra pertenece a su estadía en Puerto Rico que, como se ha señalado, constituyó para Salinas una experiencia de enorme importancia, dado que fue también el volver a zambullirse en el mar elemental de la hispanidad. Veamos cómo el poeta expresa la maduración de su mirada, cómo una remota vivencia ha ido decantando en su espíritu hasta cuajar en la palabra poética que condensa su profunda intuición.

Por las noches, soñando que te miraba, al abrigo de los párpados maduró, sin yo saberlo, este nombre tan redondo que hoy me descendió a los labios. (115)

Hemos subrayado la alusión a la mirada interior del poeta que ve cerrando los ojos que halla una realidad diferente a la que encuentra la mirada común, 'prosaica'; y, perdón por tanta referencia, pero aquí también vemos una confesión de tipo agustiniana, al encontrar en lo cotidiano lo que su alma desde siempre ha buscado:

¡Si tú has sido para mí, desde el día que mis ojos te estrenaron, el Contemplado, el constante Contemplado! (115)

A medida que más miramos la poesía de Salinas surgen nuevas conjeturas, nuevos cabos para atar, otras ideas para entrelazar, pero 
este texto se extiende ya excesivamente, por lo que, lamentándolo sólo mencionaré algunos momentos de sus últimos trabajos que me parecen indispensables. En Todo más claro (1949) vemos como fundamental esta reafirmación en la convicción de la mirada más honda, que trasciende lo sensible hasta en lo que es su manifestación de mayor belleza.

Al principio ¡qué sencillo, allí delante, qué claro!

No era nada, era una rosa

haciendo feliz a un tallo.

$\ldots \ldots$

Cosecheras de apariencias

no saben que cada una

está celando un arcano.

Hermosos sí los sentidos, pero no llegan a tanto. (125)

Los destellos de belleza terrena son sólo oscuros reflejos de la luz que resplandece más allá, donde ve clarear la mirada del poeta.

¡Tinieblas, más tinieblas!

Sólo claro el afán.

No hay más luz que la luz

que se quiere, el final. (126)

Por último, queremos destacar algunos pasajes de Confianza (póstumo), "poema de trémula esperanza, de amor a la vida, quizá porque presentía el poeta que vida y esperanza eran cosas de las que breves años podría ya disfrutar". ${ }^{79}$ El poema que da título a la obra, como lo hace notar Cano, está tejido en intertextualidad con una rima de Bécquer - poeta admirado por Salinas- que dice:

${ }^{79}$ Cano, op. cit., p. 57. 


\section{ALBERTO SAURET}

Mientras haya unos ojos que reflejen... ¡habrá poesía!

La confianza que trasunta esta obra de Salinas es la que le inspira su mirada, con la que cree ver más claro, ya su cercana muerte, “más allá de la no muerte”, como dijera en La voz... En su poesía postrera vuelve a la simbología que hemos venido subrayando, comenzando con los ojos-ventanas. Luego estos versos muy bellos y cargados de sentido,

\section{Mientras haya \\ sombras que la sombra niegan \\ pruebas de luz, de que es luz \\ todo el mundo menos ellas (149)}

donde vemos nuevamente su concepción del hombre como sombra, fugaz proyección sobre la tierra, pero también la reafirmada fe suya en que la mirada del poeta es la luz que puede iluminar el mundo y descubrir para el hombre una realidad de la que también participa y le pertenece, que es la existencia eterna de la vida misma, en un constante renacer, en un revivir sin fin. Nuevamente creemos oportuno mencionar la proximidad que encontramos en esta creencia difusa, pero al mismo tiempo firme, con la de Nietzsche barruntando, "lo que me trajo me ha de volver a traer”. Salinas termina fundiendo el pasado y lo por venir con su momento de este modo:

Memoria que le convenza

a esta tarde que se muere de que nunca estará muerta.

Mientras haya trasluces en la tiniebla claridades en secreto, noches que lo son apenas. 
PEDRO SALINAS

Tantas palabras que esperan, invenciones, clareando, -mientras hayaamanecer de poema.

Mientras haya lo que hubo ayer, lo que hay hoy, lo que venga. (150)

La fe que él expresa no tiene mayor explicitación, no es formulada en detalle, es semejante a un esbozo a mano levantada; expuesta, y quizá también así sentida, más bien como indudable sospecha, pero también sin lugar para la duda; sin la adivinación del detalle pero con el incontrastable fundamento sensitivo y vital de un alma que ha visto -aun cuando "los ojos no vieron, los oídos no oyeron”. Pero esta vaguedad, que también es ambigüedad, pluralidad e inagotabilidad de sentido, es sustancia primordial, magma, fermento, caldo de cultivo de la poesía, donde hace sus sacras abluciones el poeta. A riesgo de simplificar lo que no puede ser más simple diré que, es como si entrevista la eternidad lo temporal dejara de ser una amenaza de muerte valedera, como si el poeta supiese que afirmándose donde ya hizo pie no tiene nada que temer; en tanto que partícipe por un instante de lo eterno, él sabe que una parte de su ser no podrá perecer.

Para finalizar sólo quiero agregar dos cosas. En primer lugar cierta proximidad con otro poeta, que ayudará a reconocer mejor a Salinas. Dice Ángel del Río en el ensayo mencionado: "En los veranos de la provincia alicantina entabla amistad estrecha con Gabriel Miró, de cuyo arte, hecho de ardorosa sensualidad espiritualizada, se advertirá algún reflejo en Salinas." ${ }^{80}$ No estamos en condiciones de afirmar esta influencia, pero por cierto encontramos muy significativo lo que Salinas habrá de opinar de su amigo: "Gabriel Miró es para mí el mejor poeta de la naturaleza que ha vivido en nuestro siglo. El mismo

${ }^{80}$ Op. cit., p. 20. 


\section{ALBERTO SAURET}

soplo de misticismo panteísta de un Fray Luis de Granada transpira en sus descripciones de los paisajes de su tierra levantina, donde la nube, la sierra, el agua y la hormiga conviven en un bellísimo poema de la creación.”81 De esta cita nos interesa extraer unas palabras que nos parecen especialmente adecuadas para aplicarlas a la propia poesía de Salinas, pues creemos que en ella alienta ese soplo de misticismo panteísta.

La otra cuestión es la 'tesis de la tesis' de este trabajo. Para ello partamos de la Variación XVI, “Salvación por la luz” de El Contemplado:

Por venir a mirarla, día a día, embeleso a embeleso, tal vez tu eternidad, vuelta luz, por los ojos se nos entre.

$Y$ de tanto mirarte, nos salvemos. (122)

Sobre estos versos caben algunos de los comentarios hechos, donde decíamos que el poeta siente pertenecer al orden eterno por encima -y sobre todo por debajo: "Suelo. Ni más ni menos./Y que te baste con eso.”- de lo temporal y cambiante por haberlo aprehendido con su visión. Pero lo que nos interesa destacar ahora más es el epígrafe inscrito por Salinas para encabezar este poema: "Eche por donde eche, vía San Francisco o vía Baudelaire, Fioretti o Fleurs du mal, todo poema digno acaba en iluminaciones.” Mientras que en El defensor -más o menos por la misma época- dirá: "La palabra es luz. (...) ¿Adónde llega? Adonde quiera la voluntad del hombre que empuña el farol.”82 Con lo que se nos muestra al poeta que ve al poeta como iluminador, en su función prometeica, que como hemos puntualizado es lucha del espíritu sobreponiéndose a la materia del lenguaje, pero aquí nos lo muestra también básicamente como un acto supremo de voluntad -rasgo que también lo aproxima al vitalismo de Nietzsche.

${ }^{81}$ Literatura española..., op. cit., “El signo...”, p. 42.

${ }^{82}$ El defensor, op. cit., p. 76. 
Veamos, por último, otra versión del hombre que se despoja de las cadenas, asciende por encima de sus semejantes, ve y baja para narrar lo visto. "Un escritor, sépalo o no, nunca escribe para tan sólo los que conviven con él en su tiempo. La noción de actualidad, tan importante en otras cosas, es en el arte puro muy poco significante. (...) Las obligaciones de inteligibilidad de un poeta no tienen por qué ceñirse indispensablemente a la capacidad media de entender de su época. Si hoy no se le entiende, ¿no vendrán días mejores? Esta gran esperanza de ser algo más que una voz del hoy, abierta a la mañana, cerrada con la noche, este gran sueño de vivirse más allá, es la raíz de toda gran poesía." ${ }^{82}$ Este fragmento también nos provoca el recuerdo de otros del 'último romántico', cuando escribe "para todos y para ninguno”, cuando en Sils María, sin fanfarronería, sabe que está a miles de pies de altura “y a muchísimos más del resto de los mortales”.

La mirada del poeta es la que cierra los ojos y ve un universo más cierto que el de sombras macilentas; la poesía del poeta es un rayo de luz que nos ofrece una senda en cual confiar: es el poeta transfigurado que nos presta su mirada.

${ }^{82}$ Ibid., p. 247. 
